\title{
Implementasi Model Pembelajaran Beyond Center And Circle Time (BCCT) Sebagai Upaya Meningkatkan Kualitas Pendidikan
}

\author{
Romini \\ Sekolah Tinggi Agama Kristen Terpadu Pesat Salatiga \\ Email: elisabethromini33@gmail.com
}

Abstract

This study aims to improve the quality of education in the integrated Pniel Chiristian Kinderagarten to make it more interesting, child-centred learning, and more creative learning, and more creative learning activities. Through implementation of the Beyond Center and Circle Time (BCCT) learning model, it is hoped that it can improve the quality of education in the integrated Peniel Christian Kindergarten. The research method used was school Action Research (PTS) with teacher six apprentices, an six TOT as the research subjects. Collecting data through observation, interviews, and documentation in the form of records of child development. Te study was conducted in three cycles. The results obtained through interview with 5 Kindergarten teacher of peniel stated that: learning activities are more fun, children are more creative and play according to their interests, and children tend to want to try every variety of play facilitatated by the teacher. Children are seen to be more independent because they do their own activities and children prefer to play in the center, so that children can develop their creativity. Teachers are also motivated to facilitate in preparing various games, develop children 's intellgence based on multiple intelegences, teachers focus more on center, so that it is more fun. Paring various games, develop children's intelligence based on multiple intelligences, teachers focus more on one center, so that it is more fun to accompany children ti learn, can make objects around them as a means of learning while playing. The central learning room is equipped with appropriate and supportive play, facilities. From the 12 training participants stated: through the implementation of learning with beyond Center and circle Time (BCCT), the quality of education in the integrated Pniel Chritian Kindergarten can be increased, so that the Integrated Pniel Christian Kindergarten is chosen to be a Kindergarten pilot at the PESAT Foundation and become a training ground for PESAT kindergarten teachers.

Keywords: Implementation; Beyond Center and circle Time (BCCT); Early Childhood Education.

Abstrak

Penelitian ini bertujuan untuk meningkatkan kualitas pendidikan di TK Kristen Pniel Terpadu agar makin menarik, pembelajaran berpusat pada anak, dan kegiatan pembelajaran makin kreatif. Melalui Implementasi model pembelajaran Beyond Center and Circle Time (BCCT) di harapkan dapat meningkatkan kualitas Pendidikan di TK Kristen Pniel Terpadu. Metode penelitian digunakan dengan Penelitian Tindakan Sekolah (PTS) dengan subyek penelitian lima guru, enam peserta magang, dan enam peserta peserta TOT. Pengumpulan data 
melalui observasi, wawancara, dan dokumentasi berupa catatan perkembangan anak. Penelitian dilakukan dengan tiga siklus hasil yang diperoleh melalui wawancara kepada 5 guru TK Pniel menyatakan bahwa: kegiatan pembelajaran semakin menyenangkan, anak lebih kreatif dan bermain sesuai minatnya, dan anak cenderung ingin mencoba setiap ragam main yang difasilitasi guru. Anak lebih terlihat kemandiriannya karena melakukan kegiatan sendiri dan anak lebih senang bermain di sentra, sehingga anak dapat mengembangkan kreatifitasnya. Guru pun termotivasi untuk memfasilitasi dalam menyiapkan ragam permainan, mengembangkan kecerdasan anak berdasarkan kecerdasan majemuk, guru lebih fokus di satu sentra, sehingga lebih asyik dalam mendampingi anak belajar, dapat menjadikan benda-benda yang ada disekitar sebagai sarana belajar sambil bermain, ruang belajar/sentra diperlengkapi dengan sarana main yang sesuai dan mendukung. Dari 12 orang peserta training menyatakan: melalui penerapan pembelajaran dengan Beyond Center and Circle Time (BCCT) maka kualitas pendidikan di TK Kristen Pniel Terpadu dapat meningkat, sehingga TK Kristen Pniel Terpadu dipilih menjadi TK percontohan di Yayasan PESAT dan menjadi tempat pelatihan para-guru TK PESAT.

Kata-Kata Kunci: Implementasi; Model Pembelajaran Beyond Center and Circle Time (BCCT); Pendidikan Anak Usia Dini.

\section{PENDAHULUAN}

Pendidikan Anak Usia Dini (PAUD) merupakan upaya pembinaan yang ditujukan kepada anak sejak lahir sampai enam tahun. Usia ini merupakan masa emas (golden age) masa peka yang tidak dapat terulang kembali. Oleh sebab itu usia dini penting mendapatkan rangsangan yang tepat yang memberikan bekal anak sehingga anak siap memasuki Pendidikan Dasar selanjutnya (Novitasari \& Fauziddin, 2020).

Anak Usia $0-8$ tahun mengalami proses perkembangan dan pertumbuhan sangat cepat, anak mulai peka dalam menerima rangsangan dari lingkungan sehingga dapat mempengaruhi perkembangan kemampuan yang dimiliki (Nurani Sujiono, 2009, p. 54). Usia dini merupakan masa awal pengembangan agama, kemampuan fisik, motorik, social emosional, bahasa, kognitif, konsep diri dan kemandirian. Maka diperlukan kondisi dan stimulus dari lingkungan yang sesuai dengan kebutuhan agar pertumbuhan dan perkembangan anak tercapai secara optimal. Perkembangan jaringan otak anak yang paling menentukan terjadi ketika anak masih usia dini. Teori tabularasa mengemukakan bahwa anak seperti papan kosong yang perlu ditulisi oleh pengalaman-pengalaman yang didapat dari lingkungan anak, berbeda dengan Jean Jacques Rousseau dalam (S. Gunarso, n.d., p. 16) menyatakan bahwa setiap anak yang lahir sudah membawa segi-segi moral, baik dan buruk yang akan berkembang selanjutnya. Begitu pula dalam catatan harian Dieterich Tiedeman menemukan kemampuan anak yang dibawa sejak lahir meliputi perkembangan sensoris, bahasa, 
motorik dan intelek (S. Gunarso, n.d., p. 17). Ketika anak lahir sudah dibekali dengan kemampuan namun lingkungan memiliki peran yang sangat besar dalam pembentukan sikap, kepribadian dan pengembangan kemampuan anak. Masa berlangsungnya konsepsi hingga lahir saat itulah terbentuknya potensi yang mempengaruhi perkembangan selanjutnya (S. G. Y. Gunarso, 2011, p. 7).

Mendukung Teori tabularasa yang menyatakan bahwa lingkungan sangat mendukung perkembangan anak. Montessori menyatakan bahwa: pentingnya kondisi lingkungan yang bebas dan penuh kasih agar potensi yang dimiliki anak dapat berkembang secara optimal (Nurani Sujiono, 2009, p. 108). Lingkungan yang kaya sangat mempengaruhi perkembangan anak. Anak memiliki kemampuan untuk membangun sendiri pengetahuannya, dan hal tersebut dilakukan oleh anak mulai dari usia dini. Kondisi lingkungan yang mendukung dan lingkungan yang menyenangkan penuh kasih sayang, dapat merangsang anak berkembang dengan maksimal. Untuk mencapai tujuan yang diharapkan, maka perlunya setiap lembaga PAUD perlu menentukan model pembelajaran yang sesuai perkembangan anak. Menentukan strategi pembelajaran yang merangsang pertumbuhan sesuai tahap perkembangan anak sangat diperlukan.
Keadaan yang terjadi di TK Kristen Pniel Terpadu dalam proses pembelajaran masih berpusat pada guru. Kegiatan pembelajaran berlangsung secara klasikal, anak pasif hanya melakukan instruksi guru. Anak cenderung mengerjakan tugas-tugas dengan mengerjakan lembar kerja. Kondisi ruang kelas yang kurang menarik dan kurangnya sarana-sarana main di dalam ruang. Pembelajaran yang berpusat pada guru (Teacher Center Learning) adalah pembelajaran yang terjadi guru yang lebih aktif dan anak sebagai obyek hanya melaksanakan tugas yang diberikan oleh guru. Guru terpaku pada buku teks yang ada. Pembelajaran yang berpusat pada anak (Child centered) adanya intereaksi antara guru dengan anak dan anak yang lainnya. (wijaya, 2008).

Melihat permasalahan di atas, segeralah menyusun strategi untuk meningkatkan kualitas pembelajaran melalui model pendekatan Beyond Center and Circle Time (BCCT). Pendekatan Beyond Center and Circle Time (BCCT) merupakan model pembelajaran yang berpusat pada anak, dan pembelajaran yang sesuai dengan perkembangan anak, pembelajaran yang memberikan kesempatan anak untuk menyalurkan ideidenya, guru sebagai fasilitator menyiapkan sarana main yang diperlukan. 
Penelitian yang dilakukan yang di lakukan oleh Ridaningsih (Rindaningsih, 2012) dan penelitian yang dilakukan oleh Renti italia (Oktaria \& others, 2014) yang menerapkan pendekatan Beyond Center and Circle Time (BCCT) dalam pembelajaran pada anak usia dini, begitu pula Uswatun merancang strategi pembelajaran yang menciptakan anak aktif dapat diterapkan melalui pendekatan pembelajaran Sentra dan Lingkaran atau pendekatan (BCCT) (Hasanah, 2018). Hasil penelitiannya menyatakan bahwa melalui kegiatan bermain dengan pendekatan dalam Sentra dan Lingkaran dapat mengatasi permasalahan yang kompleks di sekolah dan memaksimalkan peran kepala sekolah menjalankan strategi di sekolah.

Carol (199:22) dalam Yuliani
dalam buku Konsep Dasar PAUD
menyatakan bahwa saat anak bermain di
sentra, anak mendapat kesempatan untuk bereksplorasi dan dapat menyalurkan kemampuannya. Melalui sentra anak dapat belajar sambil bermain (learning by doing) (Sujiono, 2009, p. Hal.22). Pada Sentra juga anak dapat belajar berhitung, menglasifikasikan sesuai bentuk dan memecahkan masalah. Jadi sentra bukan sekedar tempat anak bermain tetapi juga belajar (Kasal, 2019, p. 66).

Penelitian lain menyatakan bahwa bagaimana manejemen pembelajaran di
Taman Kanak-kanak melalui pendekatan sentra yang membuat anak lebih aktif dan kreatif (Harmawati \& Hasanah, 2020). Menurut Wismiarti dalam bukunya menyatakan bahwa melalui metode sentra dapat menempatkan anak pada posisi yang tepat, dalam proses pembelajaran anak mendapat rangsangan melalui bermain sehingga anak menjadi aktif (Kasal, 2019, p. hal 47).

Tujuan Penelitian ingin mengetahui apakah Model pembelajaran Beyond Center and Circle Time (BCCT) dapat meningkatkan kualitas pendidikan khususnya di TK Kristen Pniel Terpadu. Kualitas Pendidikan yang dimaksud dalam penelitian ini adalah mutu Pendidikan TK Kristen Pniel Terpadu dalam memberdayakan sumber-sumber pendidikan yang ada baik guru, anak, maupun sarana-sarana yang ada sehingga proses pendidikan berjalan efektif dan berkualitas.

\section{METODE PENELITIAN}

Sebagai acuan dalam memecahkan masalah yang ada maka segera dilakukan tindakan. Tindakan yang dilakukan menggunakan metode Penelitian Tindakan Sekolah (PTS). PTS merupakan penelitian yang dilakukan oleh kepala sekolah untuk menemukan cara baru untuk memperbaiki kondisi sekolah dan untuk memecahkan 
persoalan-persoalan pendidikan yang terjadi di sekolah.

Penelitian Tindakan Sekolah (PTS) merupakan penelitian yang dillaksankan oleh kepala sekolah untuk memperbaiki kualitas pendidikan (Suyadi, 2012, p. 18). Data diperoleh melalui observasi, wawancara dan dokumentasi, wawancara kepada lima guru TK Kristen Pniel, enam kepala TK Yayasan Pesat yang mengikuti program magang di TK Kristen Pniel, enam peserta TOT (Trainer Of Trainer) dari Yayasan Pesat, dan observasi terhadap perkembangan anak TK A dan TK B yang di peroleh dari catatan harian perkembangan anak, guna melihat perkembangan anak. Data yang didapat dari tujuh belas subyek di atas sudah dapat mewakili guru Pesat yang lainnya. Sebab subyek di atas langsung mempraktekan model pembelajaran BCCT saat magang di TK Pniel, dan sebagai orang berpengaruh di TK Yayasan pesat. Untuk melihat data 17 orang sebagai informan dapat dilihat pada tabel 1.1 di bawah ini:

Tabel 1

Data Informan

\begin{tabular}{|l|l|l|l|}
\hline No & $\begin{array}{l}\text { Nama } \\
\text { Inisial }\end{array}$ & Jabatan & Tempat tugas \\
\hline 1 & Eli & Kep TK & TK K Pniel \\
\hline 2 & Evi & Guru TK A & TK K Pniel \\
\hline 3 & Narti & GuruTK B1 & TK K Pniel \\
\hline 4 & Delfi & Guru KB & TK Pniel \\
\hline 5 & Elvita & GuruTK B2 & TK Pniel \\
\hline 6 & Nunuk & pesertaTOT & Pesat \\
\hline 7 & Hermin & PesertaTOT & Pesat \\
\hline 8 & Nanik & PesertaTOT & Pesat \\
\hline
\end{tabular}

\begin{tabular}{|l|l|l|l|}
\hline 9 & Usi & PesertaTOT & Pesat \\
\hline 10 & Vani & PesertaTOT & Pesat \\
\hline 11 & Rida & $\begin{array}{l}\text { Direktur } \\
\text { Litbang }\end{array}$ & Salatiga \\
\hline 12 & Sarlota & Kep TK & Kaltim \\
\hline 13 & Karlin & Kep TK & Mentawai \\
\hline 14 & Juwita & Kep TK & Ja-Teng \\
\hline 15 & Derma & Kep TK & Sibolangit \\
\hline 16 & Sista & Kep TK & Lalow (Sulut \\
\hline 17 & Dwi & Supervisor & Mentawai \\
\hline
\end{tabular}

Tabel 2

Instrumen observasi dan wawancara tentang Penerapan BCCT

\begin{tabular}{|l|l|}
\hline No & \multicolumn{1}{|c|}{ Peryataan } \\
\hline 1 & $\begin{array}{l}\text { Apakah Model Pembelajaran BCCT } \\
\text { merupakan pembelajaran yang sesuai } \\
\text { dengan tahap perkembangan anak dan } \\
\text { dapat di terapkan di TK desa? }\end{array}$ \\
\hline 2 & $\begin{array}{l}\text { Apakah Denerapan } \\
\text { pembelajaran BCCT dapat memotivasi } \\
\text { anak dan guru untuk dapat } \\
\text { mengembangkan kreatifvitasnya? }\end{array}$ \\
\hline 3 & $\begin{array}{l}\text { Apakah Anak dapat termotivasi dan } \\
\text { lebih kreatif bermain sesuai minat } \\
\text { anak? }\end{array}$ \\
\hline 4 & $\begin{array}{l}\text { Guru sebagai fasititator hendaknya } \\
\text { menyiapkan sarana main yang di } \\
\text { butuhkan dalam setiap sentra }\end{array}$ \\
\hline 5 & $\begin{array}{l}\text { Dalam pendekatan BCCT anak belajar } \\
\text { dan bermain tidak hanya dengan kertas } \\
\text { tetapi dengan benda-benda yang ada di } \\
\text { sekitar anak }\end{array}$ \\
\hline 6 & $\begin{array}{l}\text { Dengan penerapan Pendekatan BCCT } \\
\text { ini pembelajaran lebih hidup, anak } \\
\text { lebih bergairah dalam belajar, sehingga } \\
\text { anak dapat muncul ide-idenya }\end{array}$ \\
\hline 7 & $\begin{array}{l}\text { Setiap sentra dapat diperlengkapi } \\
\text { dengan sarana main yang di fasilitasi } \\
\text { guru, anak dapat bermain } \\
\text { menggunakan fungsi panca indra anak }\end{array}$ \\
\hline 8 & $\begin{array}{l}\text { Dukungan guru sangat diperlukan, } \\
\text { sebelum anak main saat anak main dan } \\
\text { setelah anak main. }\end{array}$ \\
\hline 9 & $\begin{array}{l}\text { Sebelum mengenal Pendekatan BCCT } \\
\text { ini TK Pesat masih banyak menerapkan } \\
\text { pembelajaran yang menggunakan buku } \\
\text { dan pensil saja, anak mengerjakan } \\
\text { kegiatan sesuai intruksi guru }\end{array}$ \\
\hline
\end{tabular}


10 Model Pembelajaran BCCT tepat dilakukan diseluruh TK Yayasan PESAT, sehingga mutu pembelajaran dapat meningkat

Melalui instrument wawancara ini informan diharap menjawab dengan jawaban:

1. Tidak setuju, 2. Ragu-ragu,

3. Setuju 4. Sangat setuju

Setiap siklus terdiri dari empat tahap yaitu perencanaan, pelaksanaan, pengamatan dan refleksi. Penelitian ini terdiri dari tiga siklus Siklus pertama dilakukan tahun ajaran 2017-2018, dengan tindakan yang dilakukan pelatihan kepada guru TK Pniel tentang penerapan BCCT dan perlengkapan sarana main baik di dalam maupun di luar.

Siklus ke dua, selanjunya dilakukan tahun ajaran 2018-2019 dengan tindakan meningkatkan metode pembelajaran dan perlengkapan sarana prasaran sesuai kebutuhan pembelajaran.

Siklus ke tiga tahun ajaran 2019 2020 guru berupaya makin memotivasi anak untuk menyalurkan kreativitasnya dan memperlengkapi dan menambahkan sarana- sarana main disetiap sentra.

Pada tahap perencanaan kepala sekolah memberikan trainning kepada semua guru tentang konsep dasar Beyond Center and Circle Time (BCCT). Tahap pelaksanaan semua guru mempraktikkan pembelajaran dengan metode Beyond Center and Circle Time (BCCT) pada setiap kegiatan bermain di kelas. Selanjutnya Tahap pengamatan setiap guru mengamati hasil proses belajar dan perkembangan anak

dan tahap Reflesi: dilakukan evaluasi terhadap hasil proses belajar dan meningkatkan hal-hal yang perlu di tingkatkan.

\section{PEMBAHASAN}

Model pembelajaran anak usia dini dapat di bedakan menjadi dua model yaitu pembelajaran yang berpusat pada guru yang di pelopori oleh para tokoh Bihavioris yang menyatakan bahwa prilaku setiap manusia merupakan respon dari stimulus yang di terima. Sedangkan model pembelajaran yang berpusat pada anak di pelopori oleh Piaget dan Erikson yang menyatakan bahwa anak memiliki motivasi diri yang di bawa sejak lahir. Anak mampu membangun pengetahuan sendiri dengan tersedianya lingkungan yang menyediakan peralatan atau sarana main yang mendukung anak berkembangn sesuai ritme perkembangan masing masing anak. (Nurani Sujiono, 2009).

Model Pembelajaran Beyond Center And Circle Time (BCCT)

Strategi pembelajaran di PAUD adalah keterampilan dalam mengatur 
pembelajaran dengan kiat-kiat yang sesuai untuk mencapai hasil yang maksimal. Tujuan menggunakan strategi pembelajaran adalah agar dapat mengaktifkan anak belajar dengan kondisi yang menyenangkan tanpa adanya tekanan, sehingga terjadi perubahan prilaku pada anak didik, dan menciptakan lingkungan belajar yang membantu merangsang, menantang serta mengembangkan seluruh aspek perkembangan dalam diri anak didik (Latif, Mukhtar, Zukhairina, Zukhairina, Zubaidah, Rita, 2013, pp. 99-100).

Model pembelajaran adalah suatu cara yang dirancang dalam proses pembelajaran yang menjadikan lingkungan belajar dapat memungkinkan anak berinteraksi dengan benda-benda, dengan teman sebaya yang ada di sekitarnya, anak dapat berkembang dengan maksimal.

\section{Model BCCT (Beyond Center and}

Circle Time merupakan metode belajar dan bermain yang menjadikan anak sebagai pusat pembelajaran. Suatu pendekatan pembelajaran yang merangsang kecerdasan anak melalui bermain terarah (Mentari, 2019, p. 309). Dengan bermain di sentra dapat merangsang kecerdasan anak. Guru memfasilitasi anak untuk belajar dengan menyediakan alat dan sarana main sesuai dengan jumlah anak dengan tujuan merangsang seluruh aspek kecerdasan anak melalui bermain. Pendekatan BCCT menekankan sentra atau penataan ruang kelas dengan perlengkapan sarana main sehingga anak terprovokasi dan timbul ide-ide baru dan menjadi kreatif, mampu berinisiatif sendiri atau menggali pengalaman sendiri bukan sekedar melakukan instruksi guru melalui kegiatan-kegiatan yang sudah disiapkan di sentra. Kegiatan bermain berada di sentrasentra kegiatan dan anak berada dalam lingkaran bersama pendidik. Sentra-sentra yang disediakan antara lain sentra main peran, sentra bahan alam, sentra persiapan dan sentra balok (Latif, Mukhtar, Zukhairina, Zukhairina, Zubaidah, Rita, 2013, p. 121). Pendekatan Beyond Center and Circle Time (BCCT) dapat meningkatkan kemampuan bahasa anak seperti penelitian yang dilakukan oleh Nina Widiati (Widiyati, 2012).

Dengan pembelajaran sentra dapat menempatkan anak pada posisi yang proposional. Anak dirangsang dengan bermain sambil belajar. Ada beberapa sentra yang dapat dikenalkan pada anak, dimana anak dapat belajar dan bermain.

\section{Sentra Persiapan}

Sentra persiapan adalah ruang belajar yang difokuskan pada kegiatan pembelajaran yang berfokus untuk mengembangkan kognisi, motorik halus, keaksaraan, dan kegiatan matematika, serta membaca dan menulis (Latif, Mukhtar, Zukhairina, Zukhairina, Zubaidah, Rita, 
2013, p. 124). Pada tahap ini, anak diberi kesempatan untuk mengklasifikasikan, mengurutkan, membuat pola dan mengorganisasikan alat-alat main.

Perlengkapan main di sentra persiapan antara lain adalah alat main yang mendukung proses klasifikasi misalnya manik-manik, mozaik, halma, papan geomitri, tibangan, puzzle. Alat main lain yang mendukung keaksaraan, kartu huruf, alat tulis, dan alat main yang mendukung keterampilan motorik halus: jepitan, gunting, alat-alat menggambar dan lainnya.

Di sentra persiapan, anak diarahkan untuk mempersiapkan kematangan kemampuan dasar sehingga anak siap untuk masuk ke sekolah dasar. Walaupun demikian, di sentra persiapan hendaknya memotivasi anak melakukannya dengan senang dan gembira (Kasal, 2019, p. 171).

\section{Sentra Balok}

Sentra Balok adalah Sentra yang disiapkan untuk mengembangkan kemampuan berpikir dengan media pembangunan terstruktur. Tujuannya meningkatkan kemampuan kontruksi membuat garis lurus ke atas, ke representasi, bermain sendiri ataupun kelompok kecil. Di sentra balok memiliki esensi membangun stuktur berpikir anak.

Perlengkapan main di sentra balok berupa balok berbagai ukuran, assesooris balok (misalnya boneka keluarga, profesi, rambu-rambu lalu lintas, kendaraan), alas balok dengan warna dasar, kertas, karayon, spidol, meteran, gunting, dan yang lainnya (Latif, Mukhtar, Zukhairina, Zukhairina, Zubaidah, Rita, 2013, p. 131).

Di sentra balok anak merancang ide atau gagasannya dengan balok-balok berbagai ukuran dan balok-balok assesorisnya.

\section{Sentra Peran}

Sentra peran terdiri dari peran besar dan kecil pada sentra main peran besar adalah sentra yang memberikan kesempatan anak untuk mengembangkan pengetahuan tentang dunia sekitarnya dengan bermain pura-pura, bermain drama, dokter-dokteran, peran ayah, peran ibu, dan peran binatang-binatangan. Dalam bermain peran besar ini anak dapat mengembangkan kemampuan intereaksi sosial dan bahasa, membangun rasa empati dan afeksi.

Sentra main peran kecil adalah bermain simbolik, bermain pura-pura dengan menggunakan benda-benda kecil dan menggerak-gerakannya. Jadi anak berperan sebagai dalang. Anak diberi kesempatan untuk mengembangkan kemampuan berinteraksi sosial, berbahasa, membangun kemampuan abstrak berpikir dan berpikir secara obyektif. 
Perlengkapan main di sentra peran antar lain permainan alat-alat rumah tangga, benda-benda berukuran mini, mobil-mobilan, binatang-binatangan, rumah-rumahan, boneka, pesawat, pohonpohonan, maket bangunan, boneka orang dan binatang, assesoris perlengkapan memasak, perlengkapan makan, dan alat main yang mendukung keaksaran lainnya (Latif, Mukhtar, Zukhairina, Zukhairina, Zubaidah, Rita, 2013, p. 132).

Dengan main peran anak mengembangkan kemampuan interaksi sosial dengan temannya. Begitu pula dapat membangun kemampuan berbahasa, dan dengan demikian kosa kata anak akan bertambah.

\section{Sentra Bahan Alam}

Sentra ini memberi kesempatan kepada anak untuk berinteraksi dengan benda-benda sekitarnya untuk mengembangkan kemampuan sensorismotor dan mengembangkan kemampuan mengontrol diri, belajar dengan bermain sains. Anak usia 1-3 tahun banyak bermain di sentra bahan alam, dengan bermain di sentra bahan alam anak dapat belajar membangun control gerak dan emosinya yang masih rendah dan anak belajar untuk dapat berkonsentrasi lebih lama dengan demikian anak akan lebih siap bermain di sentra lain (Kasal, 2019, p. hal 164).
Perlengkapan main di sentra bahan alam antara lain playdough, figerpainting, cat lukis, beras, biji-bijian, pasir, air, krayon spidol dan alat-alat untuk menakar dan menuang. Di sentra bahan alam ini memberikan kesempatan anak untuk berekplorasi sains, misalnya mencampur warna, membuat warna baru. Bagi anak usia 1-2 tahun dapat membangun sensorismotor, bagi anak usia 2-4 tahun tahapan bermain air dapat berkembang, untuk anak 4-6 tahun sentra bahan alam sebagai sumber untuk berekplorasi sains (Kasal, 2019, p. 154).

\section{Sentra Seni}

Sentra seni anak diberi kesempatan untuk mengembangkan kemampuan berintereaksi menggunakan berbagai bahan kertas berwana, peralatan menggunting, lem, playdough, krayon, kain flannel. Selain itu, anak diberi ruang untuk berkreasi, dengan cat warna-warni, dan mengembangkan kemampuan motorik halus.

Perlengkapan main di sentra seni antara lain krayon, cat, kuas, macammacam kertas warna, bahan bekas, kanji warna, kain perca, dan macam-macam benang (Latif, Mukhtar , Zukhairina, Zukhairina , Zubaidah, Rita, 2013, p. 135).

Metode Beyond Center and Circle Time (BCCT) menerapkan tiga jenis main, yang pertama main sensoris motor yaitu 
anak bermain menggunakan benda-benda untuk membangun persepsi. Unsur main peran yaitu anak bermain dengan benda dan kostum-kostum untuk bermain peran dengan konsep yang dimilikinya. Ketiga unsur pembangunan yaitu anak bermain dengan benda-benda untuk mewujudkan idenya menjadi bentuk nyata.

Pada setiap sentra main menerapkan empat tahapan (scaffolding) untuk memberikan dukungan kepada anak. Empat tahapan adalah : dukungan saat penataan lingkungan tempat anak bermain , dukungan yang diberikan sebelum main, dukungan saat main dan dukungan setelah main (Direktorat pendidikan Anak Usia Dini, n.d., pp. 9-17). Begitu pula dalam penelitian Eny Suprihatin yang menyatakan bahwa scaffolding dapat menolong anak mengembangkan kemampuannya (Suprihatin \& Rosita, 2020, p. 2).

Tahap scaffolding antara lain adalah pijakan lingkungan main yang disediakan oleh guru. Caranya guru menata lingkungan dengan memperhatikan jumlah anak dan ragam main yang disiapkan dengan rumus intensitas dan densitas. Guru menyiapkan lingkungan main yang menarik dan menantang, menyiapkan sarana main yang diperlukan anak dalam berekplorasi di sentra (Mulyasa, n.d., p. hal 157).
Pada pijakan sebelum main, guru mengajak anak membentuk lingkaran, mengajak berdoa bersama, menanyakan kesiapan dan perasaan anak, kemudian memulai bercerita menggunakan media sesuai tema dan menginformasikan jenis mainan yang akan dimainkan anak dan menyampaikan aturan main.

Selain itu, pada pijakan saat main guru menyiapkan catatan untuk mencatat celoteh anak dan yang dilakukan anak, perilaku dan sikap anak saat bermain. Guru membantu anak jika dibutuhkan dan mengingatkan anak jika ada yang melanggar aturan. Anak diberikan kesempatan untuk berekplorasi dengan benda-benda yang ada, di sini akan muncul gagasan anak untuk melakukan sesuatu dan menciptakan suatu hasil karya.

Pada pijakan setelah main, guru meminta peserta didik membereskan mainan kemudian meminta anak menceritakan pengalaman dan perasan anak saat main, dapat juga anak menceritakan pengalaman saat bermain melalui gambar. Setelah selesai, saatnya mentutup doa bersama dan menginformasikan kegiatan esok hari (Mentari, 2019, p. 318).

Langkah kedua tindakan yang dilakukan adalah semua guru mengatur ruang kelas menjadi lima sentra dan memperlengkapi sarana main di setiap sentra. Lima sentra itu adalah sentra: 
balok, peran, bahan alam, persiapan, dan Seni. Ditambah satu sentra lagi yang dilakukan satu minggu sekali adalah sentra memasak. Di sentra memasak anak belajar mengenal alat-alat teknologi memasak, fungsi dan bagaimana cara menggunakan nya. Alat-alat tersebut antara lain: Panci, wajan, baskom, pisau, blender, rice cooker, kompor gas, tabung gas dan alat-alat dapur yang lain nya. tentunya perlu di jelaskan kepada anak bagaimana cara menggunakan nya, rti pisau gunanya untuk memotong, cara memegang, dan cara menggunakan nya. bahaya nya jika tidak tidak benar cara menggunaknya. Anak belajar memotong, memetik sayuran, menumbuk bumbu, menggoreng dan memasak serta merasakan masakan makanan yang sudah disepakati.

\section{Hasil observasi dan wawancara}

\section{Hasil siklus pertama}

Langkah pertama yang dilakukan pada penelitian tindakan sekolah dalam tahap perencanaan kepala sekolah memberikan pelatihan kepada guru tentang Model pembelajaran Beyond Center and Circle Time (BCCT). Setelah melaksanakan penerapan pembelajaran BCCT dan melakukan pengamatan, dan saat merekfeksi guru menyampaikan pengalamannya bahwa guru semakin paham dan anak semakin kreaktif. Para guru menyatakan bahwa melalui metode pendekatan Beyond Center and Circle Time (BCCT) dapat menjadikan kegiatan pembelajaran semakin menyenangkan. Anak lebih kreatif dan bermain sesuai minatnya. Anak cenderung ingin mencoba setiap ragam main yang difasilitasi oleh guru. Anak juga lebih terlihat kemandiriannya karena melakukan kegiatan sendiri. Selain itu, anak lebih senang bermain di sentra dan dapat mengembangkan kreativitasnya, begitu pula setiap guru sentra menjadi termotivasi untuk memfasilitasi dalam menyiapkan ragam main, yang mengembangkan kecerdasan anak berdasarkan kecerdasan majemuk, Wismiarti dalam bukunya yang berjudul "Sentra" menyatakan bahwa saat anak bermain di sentra dapat mengembangan kecerdasan lingusitik, kecerdasan matematik, kecerdasan musikal, kecerdasan kinestetik, spasial, kecerdasan interpersonal dan intrapersonal, kecerdasan naturalis serta kecerdasan eksistensial anak (Kasal, 2019, pp. 194201).

Hasil siklus 2 ditemukan bahwa guru semakin memahami dan mampu mempraktikkan metode mengajar yang yang makin kreatif memunculkan ideidenya. Melakukan kegiatan bermain yang di pilihnya.

Dalam penerapan pendekatan BCCT, guru lebih fokus pada satu sentra 
sehingga lebih asyik dalam mendampingi anak belajar, dapat memanfaatkan bendabenda yang ada di sekitar untuk menjadi alat belajar dan bermain. Ruang belajar sentra diperlengkapi dengan sarana belajar yang sesuai dan yang mendukung. Guru lebih terarah dalam menyampaikan setiap materi dan anak lebih mudah berintereaksi dengan temannya dalam kelompok dan berinteraksi dengan guru saat bermain dan saat lingkaran.

Guru-guru sentra, TK Kristen Pniel Terpadu menyatakan bahwa pendekatan Beyond Center and Circle Time (BCCT) sangat tepat diterapkan dalam kegiatan belajar dan bermain di TK Kristen Pniel Terpadu.

Pada tahun ajaran 2018-2019 yang merupakan siklus tiga dalam pelaksanan penerapan model pendekatan Beyond Center and Circle Time (BCCT). Proses Belajar di TK Kristen Pniel Terpadu ini makin terlihat lebih mapan, dan hal ini terlihat dari kegiatan main dan saranaprasarana yang makin bertambah dan didukung dengan penataan ruang/sentra yang lebih baik. Proses kegiatan belajar lebih menarik, anak terlihat semangat, kreatif, dan antusias. Apa yang dilakukan oleh TK Kristen Pniel Terpadu, ini berdampak positif bagi Yayasan Pesat sehingga Yayasan memutuskan TK Kristen Pniel Terpadu sebagai percontohan dan di jadikan tempat magang dan tempat pelatihan untuk guru-guru Taman KanakKanak Yayasan PESAT yang kemudian juga dijadikan acuan standar bagi TK-TK di bawah naungan Yayasan Pesat yang kini berjumlah 103 Taman Kanak-kanak.

Melalui wawancara kepada kepala Taman Kanak-Kanak yang pernah mengikuti magang, dan yang pernah observasi di TK Kristen Pniel Terpadu, tentang Penerapan Model Beyond Center and Circle Time (BCCT) menyatakan bahwa pembelajaran yang diterapkan dengan model BCCT membuat anak dan guru kreatif, walaupun kegiatan dilakukan setiap hari selama tiga jam tetapi anak tidak bosan, kegiatan pembelajaran di TK Kristen Pniel Terpadu sangat baik, menarik dan kreatif. Anak diberikan kebebasan memilih kegiatan bermain sendiri, dan membuat anak memiliki inisiatif. Pembelajarannya fokus pada anak, penataan ruang/sentra sangat menarik dan mendukung kegiatan pembelajaran di setiap sentra, guru lebih terarah dalam menjelaskan materi yang akan dikerjakan oleh anak. Anak lebih fokus bermain di sentra.

Untuk memastikan apakah model pembelajaran BCCT dapat di terapkan di TK Yayasan Pesat, Hasil wawancara kepada kepala TK Yayasan Pesat yang mengikuti magang di TK Pniel dan peserta TOT menyatakan 6 informan menyatakan 
sangat setuju 6 informan menyatakan setuju.

\section{Peningkatan Kualitas}

Meningkatnya kualitas TK Kristen Pniel Terpadu antara lain, hasil observasi tentang sarana dan prasarana TK Kristen Pniel Terpadu, sudah memiliki sarana belajar di dalam sesuai sentra dengan kategori baik. Guru makin kreatif dan melakukan fungsinya sebagai fasilitator. Penataan ruang sentra lebih menarik. Kegiatan Pembelajaran makin menarik dan tidak membosankan. Anak makin antusias, bergairah dan kreatif. TK Kristen Pniel Terpadu memiliki lima sentra belajar, sehingga kegiatan belajar makin bervariasi. Hasil kegiatan belajar mulai terlihat terfokus, guru kreatif, anak juga mudah beradaptasi dengan lingkungan temannya serta dapat membuat anak lebih kreatif serta mandiri. Hasil kegiatan belajar makin terasa menyenangkan baik bagi guru maupun bagi anak. Anak lebih terarah, terbiasa berinisiatif dalam melakukan kegiatan belajar dan bermain, lebih mudah bekerja sama dalam kelompok.

Guru lebih paham fungsinya sebagai fasilitator dalam menyiapkan sarana main dan memberi kesempatan anak memilih kegiatan main dan melakukannya sendiri sesuai kemampuannya. Kegiatan belajar makin terlihat hidup, anak aktif, dan kreatif serta tidak membosankan. Guru makin termotivasi untuk menggali ketrampilan dalam menyiapkan ragam main. TK Kristen Pniel Terpadu di jadikan tempat magang bagi guru -guru TK Yayasan Pesat yang tersebar di beberapa wilayah di Indonesia.

Tabel 3

Hasil Observasi dan wawancara

\begin{tabular}{|c|c|c|}
\hline NO & INFORMAN & PERYATAAN \\
\hline 1 & $\begin{array}{c}5 \text { orang guru } \\
\text { TK Pniel }\end{array}$ & Sangat setuju \\
\hline 2 & $\begin{array}{c}\text { 6 Kepala TK } \\
\text { pesat peserta } \\
\text { magang }\end{array}$ & Sangat setuju \\
\hline 3 & $\begin{array}{c}\text { 6 orang } \\
\text { peserta TOT }\end{array}$ & Setuju \\
\hline
\end{tabular}

Tabel 4

Hasil observasi perkembangan anak

\begin{tabular}{|l|c|c|c|}
\hline Kelas & Jumlah & $\begin{array}{c}\text { Hasil } \\
\text { pengamatan }\end{array}$ & $\begin{array}{c}\text { Capaian } \\
\text { akhir }\end{array}$ \\
\hline TK A & 8 anak & $\begin{array}{c}\text { Berkembang } \\
\text { sesuai } \\
\text { harapan }\end{array}$ & BSH \\
\hline TK B & 17 anak & $\begin{array}{c}\text { Berkembang } \\
\text { sangat baik }\end{array}$ & BSB \\
\hline KB & 11 anak & $\begin{array}{c}\text { Berkembang } \\
\text { sesuai } \\
\text { Harapan }\end{array}$ & BSH \\
\hline
\end{tabular}

Dapat dilihat pada tabel di atas hasil wawancara kepada para informan dapat disimpulkan dari 10 peryataan hasil jawaban adalah setuju dan sangat setuju. Model pembelajaran BCCT dapat meningkatkan kualitas pembelajaran dan dapat di terapkan di TK-TK Yayasan Pesat yang tersebar di desa-desa di wilayah Indonesia. 


\section{KESIMPULAN}

Berdasarkan uraian di atas hasil Implementasi Model Pembelajaran BCCT di TK Kristen Pniel Terpadu dapat merubah konsep belajar yang di alami oleh Guru TK Kristen Pniel Terpadu dan proses kegiatan belajar menjadi lebih menarik, tidak membosankan. Guru makin tertantang melakukan fungsinya sebagai fasilitator, dan anak makin mampu memunculkan kreativitasnya. Lingkungan belajar di TK Kristen Pniel Terpadu makin mendukung anak dengan penataan sarana main di setiap sentra., sehingga TK Kristen Pniel Terpadu menjadi Tempat percontohan dan tempat magang untuk kepala TK Yayasan pesat yang tersebar di desa-desa diwilayah Indonesia. Model Pembelajaran Beyond Center and Circle Time (BCCT) mampu meningkatkan kualitas Pendidikan TK Kristen Pniel Terpadu.

\section{Tindak Lanjut}

TK Kristen Pniel Terpadu akan lebih meningkatkan kemampuannya dalam setiap proses kegiatan pembelajaran dan dalam kekurangan kekurangan yang lain, sebab setiap tahun menghadapi anak yang berbeda-beda. TK Kristen Pniel Terpadu akan menambahkan sarana-sarana main yang masih perlu dilengkapi. Begitu pula akan selalu membuat perencanaan yang matang dalam mengadakan evaluasi pembelajaran secara terus menerus, dan setiap guru harus senantiasa mengembangkan diri dengan membaca buku-buku yang menunjang kegiatan pembelajaran yang sesuai perkembangan zaman ini. Perlunya meningkatkan kemampuan menggunakan alat-alat teknologi dalam kegiatan pembelajaran.

Dalam penerapan model pembelajaran Beyon Center and Circle Time $(B C C T)$ diperlukan pendidik yang memiliki ketrampilan dalam membuat perencanaan, mengelola kelas dan memberikan dukungan kepada anak dengan memfasilitasi sarana main yang mendukung (Mentari, 2019).

\section{DAFTAR PUSTAKA}

Direktorat pendidikan Anak Usia Dini. (n.d.). pedoman penerapan pendekatan"beyond centers and circles time $(B C C T)$ " (pendekatan centra dan lingkatan dalam Pendidikan Anak usia Dini.

Gunarso, S. (n.d.). Dasar dan teori Perkembangan (3rd ed.). PT BPK Gunung Mulia.

Gunarso, S. G. Y. (2011). Psikologi Perkembangan Anak dan Remaja. BPK Gunung Mulia.

Harmawati, D., \& Hasanah, N. (2020). Manajemen Pembelajaran Taman Kanak-Kanak Model Sentra dengan 
Pendekatan Beyond Centers And Circle Time (BCCT). PEMBELAJAR: Jurnal Ilmu Pendidikan, Keguruan, Dan Pembelajaran, 4(1), 30-33.

Hasanah, U. (2018). Strategi Pembelajaran Aktif untuk Anak Usia Dini. INSANIA: Jurnal Pemikiran Alternatif Kependidikan, 23(2), 204222.

Kasal, R. (2019). Sentra Membangun Kecerdasan Dan Kemampuan Anak Sejak Usia Dini Demi Masa Depan Yang Cemerlang (1st ed.). Mizan Anggota IKAPI.

Latif, Mukhtar, Zukhairina, Zukhairina , Zubaidah, Rita, A. M. (2013). Orentasi Baru Pendidikan Anaka Usia Dini:Teori dan Aplikasi (1st ed.). Kencana.

Mentari, E. G. (2019). Model Pembelajaran Beyond Center and Circle Time (BCCT). In Model-model Pembelajaran Anak Usia Dini. ArRuzz Media.

Mulyasa, M. (n.d.). Manejemen PAUD (5th ed.). PT Remaja Rosdakarya.

Novitasari, Y., \& Fauziddin, M. (2020). Perkembangan Kognitif Bidang Auditori pada Anak Usia Dini. Jurnal Obsesi: Jurnal Pendidikan Anak Usia Dini, 5(1), 805. https://doi.org/10.31004/obsesi.v5i1. 640

Nurani Sujiono, Y. (2009). Konsep Dasar
Pendidikan Anak usia dini.

Oktaria, R., \& others. (2014). Evaluasi Program Implementasi Pendekatan Beyond Centers And Circle Time (BCCT). Jurnal Pendidikan Usia Dini, 8(2), 337-352.

Rindaningsih, I. (2012). Pengembangan Model Manajemen Strategik Berbasis (beyond center and circle Time) bcct Pada Paud. PEDAGOGIA: Jurnal Pendidikan, 1(2), 213-223.

Sujiono, Y. N. (2009). Konsep Dasar Pendidikan Anak Usia Dini. Indeks.

Suprihatin, E., \& Rosita, D. (2020). Penerapan Teknik Scaffolding Sebagai Upaya Meningkatkan Kemandirian Belajar Anak Usia 5-6 Tahun Di Tk Kristen Kadasituru Terpadu. EDULEAD: Journal of Christian Education and Leadership, 1(1), 34-55.

Suyadi, S. (2012). Buku panduan guru profesional penelitian tindakan kelas (PTK) dan Penelitian Tindakan Sekolah (PTS). Andi.

Widiyati, N. (2012). Upaya Peningkatan Kemampuan Bahasa Anak melalui Model BCCT di Sentra Peran pada KB Anak Sholeh Colomadu Karanganyar Tahun Pelajaran 2011/2012 (Penelitian Tindakan Kelas). Universitas Muhammadiyah Surakarta.

wijaya, W. (2008). Kurikulum pendidikan 
Anak usia Dini (1st ed.). Uiversitas

terbuka. 